\title{
Identitas digital: Konstruksi identitas pada pameran karya seni Biennale Jawa Timur 8
}

\author{
Jokhanan Kristiyono ${ }^{\mathrm{a}, 1^{*}}$, Rachmah Ida ${ }^{\mathrm{b}, 2}$ \\ a Sekolah Tinggi Ilmu Komunikasi-Almamater Wartawan Surabaya, Jalan Nginden Intan Timur 1 No. 18, \\ Surabaya, 60118, Indonesia \\ b Universitas Airlangga, Jalan Airlangga No.4 - 6, Surabaya, 60115, Indonesia \\ ${ }^{1}$ jokhanan.k@stikosa-aws.ac.id; ${ }^{2}$ rachmah@gmail.com
}

* Corresponding Author

\begin{tabular}{l}
\hline INFO ARTIKEL \\
\hline Sejarah Artikel: \\
Diterima: 10 Mei 2021 \\
Direvisi: 26 Agustus 2021 \\
Disetujui: 6 September 2021 \\
Tersedia Daring: 31 Oktober \\
2021
\end{tabular}

ABSTRAK

Biennale merupakan pameran dan diskusi karya seni yang rutin diadakan setiap dua tahun. Tahun 2019 merupakan kegiatan Biennale Jawa Timur (Jatim) ke-8 dengan tema “GAS TOK! Lebur Sakjeroning Jawa Timur" melibatkan 500 seniman dan 40 kurator, terdiri 65 kegiatan yang tersebar di 16 kota dan kabupaten di Jawa Timur. Berbeda dengan

Kata Kunci:

Analisa Wacana Digital

Biennale Jatim

Identitas Digital kegiatan Biennale Jatim sebelumnya, tahun ini lokasi pameran tersebar di berbagai daerah Jawa Timur. Seluruh arsip data dan dokumentasi rangkaian Biennale Jatim 8 dikumpulkan dan dipublikasikan melalui akun Instagram @jatimbiennale8 sebagai bentuk identitas gerakan komunitas Biennale Jawa Timur. Gelaran Biennale Jatim 8 merupakan sebuah perayaan dan imajinasi bersama yang bersifat inklusif. Penelitian ini mengangkat permasalahan tentang konstruksi identitas komunitas Biennale Jatim. Metode analisa wacana digital dalam penelitian ini menganalisa kontruksi identitas yang diciptakan oleh Biennale Jatim 8 melalui media komunikasi digital media sosial Instagram. Akun Instagram @jatimbienale8 dan @biennalejatim menjadi obyek penelitan analisa wacana kontruksi identitas, dan praktik seni yang terjadi pada Biennale Jatim. Hasil penelitian ini menunjukkan sebuah wacana perubahan dan perlawanan terhadap kegiatan Biennale Jatim sebelumnnya. Perubahan ditunjukkan dari segi penyelanggara, pendanaan, format acara, lokasi berlangsungnya kegiatan, dan kerja kuratorial. Biennale Jatim 8 mendobrak dan melawan stigma tersebut. Diskursus kontruksi identitas baru tersebut ditunjukkan dengan jelas dan tegas pada proses produksi karya seni, pameran Biennale hingga pasca pameran melalui media sosial Instagram @biennalejatim8 yaitu identitas digital Biennale Jatim.

Keywords:

Digital Discourse Analysis

East Java Biennale

Digital Identity

\section{ABSTRACT}

Biennale, an art event (visual) both exhibition and discussion of artworks, comes on regularly every two years. 2019 is the 8th East Java (Jatim) Biennale with the theme "GAS TOK! Lebur Sakjeroning Jawa Timur" involves 500 artists and 40 curators, consisting of 65 activities spread across 16 cities and regencies in East Java. Unlike the previous East Java Biennale, the exhibition locations are spreading across various regions of East Java. All data archives and documentation of the East Java 8 Biennale series are collected and published through the @jatimbiennale8 Instagram account as a form of identity for the East Java Biennale community movement. The 8th East Java Biennale is a celebration and shared inclusive imagination. This research raises the issue of the identity construction of the East Java Biennale community. The digital discourse analysis method in this study analyzes the identity construction created by the East Java 8th Biennale through the digital communication media of Instagram social media. Instagram accounts @jatimbienale8 and @biennalejatim became the object of research on the discourse analysis of 
identity construction and art practices at the East Java Biennale. The results of this study indicate a discourse of change and resistance to the previous East Java Biennale activities. The changes show organization, funding, event format, location of activities, and curatorial work. The 8th East Java Biennale breaks and fights the stigma. The discourse on constructing a new identity is clearly and unequivocally demonstrated in the art production process, the Biennale exhibition, and post-exhibition through social media Instagram @biennalejatim8, the digital identity of the East Java Biennale.

(C) 2021, Kristiyono \& Ida This is an open access article under CC-BY-SA license (c) (1) ()

How to Cite: Kristiyono, J., \& Ida, R. (2021). Identitas digital: Konstruksi identitas pada pameran karya seni Bienalle Jawa Timur 8. Satwika : Kajian Ilmu Budaya dan Perubahan Sosial, 5(2), 187 198, https://doi.org/10.22219/satwika.v5i2.16514

\section{Pendahuluan}

Biennale merupakan kegiatan karya seni (rupa) yang tidak hanya berupa pameran karya, tetapi juga diskusi atau seminar tentang seni. Kegiatan ini rutin diselenggarakan setiap dua tahun sekali. Beberapa wilayah di Indonesia yang rutin menggelar Biennale selain Jawa Timur, yaitu Biennale Yogyakarta, Biennale Jakarta, dan Biennale Makasar. Biennale Jatim merupakan perhelatan akbar dua tahunan yang rutin digelar sejak 16 tahun lalu. Kegiatan ini menampilkan perkembangan seni rupa di Jawa Timur dan hubungannya dengan perkembangan seni rupa global. Biennale Jatim mencakup wilayah satu provinsi Jawa Timur. Keberadaan Biennale Jatim yang tak kunjung hadir menjelang penghujung tahun 2019, membuat para perupa muda Jawa Timur mengambil alih dan berinisiasi membuat gelaran tersebut secara swadaya. Persiapan yang dikerjakan hanya dalam kurun waktu kurang dari sebulan, yaitu bulan November-Desember 2019.

Kehadiran Biennale Jatim 8 berbeda dengan beberapa perhelatan sebelumnya, baik dari segi penyelanggaran, pendanaan, format acara, lokasi, hingga kerja kuratorial. Jika selama ini ajang Biennale adalah event yang dianggap sakral, prestise, mewah, adiluhung, kualitas super, dilarang remehtemeh, justru Biennale Jatim 8 berusaha mendobrak stigma tersebut. Biennale Jatim
8 mengangkat tema "GAS TOK! Lebur Sakjeroning Jawa Timur", dengan memposisikan gelaran Biennale Jatim sebagai milik bersama masyarakat Jawa Timur, yaitu sebagai sebuah perayaan dan imajinasi bersama yang bersifat inklusif. Semua seniman, baik kelompok ataupun individu di Jawa Timur, dapat ambil bagian dengan membayangkan, merancang, dan menjalankan kegiatan mereka sendiri. Ini merupakan pergerakan sosial komunitas seni sebagai perlawanan ideologi menjadi identitas baru oleh seniman kontemporer Jawa Timur (Laraña, Gusfield, \& Johnston, 2009; Hudayana, 2021).

Biennale Jatim 8 berlangsung pada 20 Desember 2019 hingga 20 Januari 2020, melibatkan \pm 500 seniman dan \pm 40 kurator atau penyelengara. Seluruh rangkaian Biennale Jatim 8 terdiri atas \pm 65 kegiatan yang tersebar di 16 kota dan kabupaten di Jawa Timur. Seluruh arsip data dan dokumentasi kegiatan rangkaian Biennale Jatim 8 dikumpulkan dan dipublikasikan melalui akun Instagram @jatimbiennale8. Setelah penyelenggaraan, seluruh data dan dokumentasi tersebut diolah dan diterbitkan sebagai post-event catalogue dan pameran arsip (Ida, 2010). Panita Biennale Jatim bersalin rupa menjadi jaring penghubung dan sarana perluasan dari setiap inisiatif atau acara yang diusulkan. Kegiatan dalam rangkaian Biennale Jatim 8 tidak lagi monosentris yang mempunyai venue 
mahkota (lokasi utama) sebagai kegiatan utama seperti Biennale pada umumnya. Semua kegiatan baik skala besar atau kecil adalah sama dan utama (Effendy, 2012; Voragen, 2013).

Bentuk dominasi dan hegemoni budaya sangat kental muncul pada proses produksi karya seni hingga pameran instalasi pada kegiatan Biennale, seperti penentuan tempat pameran sebagai crown venue selalu menempatkan kota besar sebagai lokasi pameran. Hal ini juga termasuk pemilihan karya seni dan seniman yang berpartisipasi pada Biennale. Karena selama ini Biennale Jatim selalu berafiliasi dengan pemerintahan, yaitu Kementerian Pendidikan dan Kebudayaan, maka dominasi penguasa (dalam hal ini pemerintah) ikut berpartisipasi dalam proses produksi karya hingga pameran karya. Selain itu hegemoni budaya arus utama, khususnya bentuk karya seni seperti seni lukis, masih cukup kental dalam proses produksi karya seni yang dipamerkan dalam Biennale Jatim. Ini menjadi permasalahan sosial tersendiri dalam komunitas seni Biennale Jatim yang saat ini sudah banyak diisi oleh seniman-seniman muda dengan ber-platform digital (Black, Castro, \& Lin, 2015; Pavlik, 2008).

Permasalahan lain yang juga muncul pada kegiatan Biennale di Indonesia yaitu mengenai pemberian penghargaan karya seni. Ini berawal dari Pameran Besar Seni Lukis Indonesia (PBSLI) pada 1974 oleh Dewan Kesenian Jakarta. Penghargaan karya seni yang bersifat nasional dipelopori PBSLI yang berganti nama menjadi Biennale Jakarta pada 1982, memberikan penghargaan pada karya terbaik melalui mekanisme penjurian. Permasalahan yang muncul pasca pemberian penghargaan tersebut menimbulkan persepsi dan opini yang berbeda tentang karya seni yang baik kala itu.

Perubahan dalam PBSLI dan Biennale Jakarta menunjukkan pengaruh dari latar sosial tempat berlangsungnya penghargaan atau lokasi pameran. Respon publik pada pemberian penghargaan, kesesuaian antara karya pemenang dengan semangat pada eranya sering menjadi persoalan yang menyudutkan dewan juri (Atmadiredja \& Adriati, 2020). Dewan juri kerap dikaitkan dengan kepentingan tertentu, ideologi, norma dan geopolitik, terutama pada masa awal PBSLI tahun 1974 hingga 1980.

Dewan juri pro pemerintah (penguasa), mereduksi karya-karya yang bermuatan kritis terhadap pemerintah. Periode 1982 hingga 1989, yaitu Biennale Jakarta, dewan juri dituduh sebagai agen dari pengusaha. Karya seni yang terpilih merupakan karya dari seniman yang sudah jadi, karya seni untuk dikoleksi. Proses dan tujuan pemilihan karya seni tidak memihak pada rakyat. Akan tetapi, dewan juri bukan satu-satunya faktor penentu selera pada medan seni rupa. Selain faktor dewan juri dengan segala persoalannya, faktor lain yang menjadi penentu adalah pola hidup masyarakat, dana, jejaring, dan opini yang dibangun melalui media massa pada era tersebut (Kusmara, 2019).

Mulai PBSLI 1974 hingga Biennale 1989, infrastruktur seni rupa Indonesia belum terbangun dengan baik dan belum banyak galeri-galeri swasta yang muncul. Dewan Kesenian Jakarta (DKJ) bersama jajaran dewan yang terdiri dari unsur budayawan dan seniman senior menjadi wacana utama. Pada periode setelah tahun 1980, kemunculan galeri dan kolektor yang memiliki perspektif dan pandangan seni tersendiri. Perspektif yang tidak menjadikan DKJ sebagai pedoman dan panduan dalam apresiasi seni lukis Indonesia (Atmadiredja \& Adriati, 2020).

Pada 2017, Biennale Jatim menyelenggarakan pameran di Kota Surabaya dengan menggangkat tema "World is HOAX". Biennale yang merupakan bagian dari komunitas seni digital Indonesia telah menjadi bentuk kritik dan perlawanan diam-diam terhadap hegemoni sosial. Hegemoni sosial merujuk pada ideologi, norma, aturan, dan mitos yang ada dalam masyarakat modern di Indonesia. Bentuk perlawanan terhadap disrupsi informasi pada masyarakat informasi di Indonesia, 
informasi yang berlebihan dan cenderung informasi yang salah berupa konten tipuan atau hoax. Informasi hoax mengacu pada orang-orang yang hidup di dunia media siber dengan semua implikasi sosialnya (Kristiyono \& Ida, 2019). Fenomena ini menjadi permasalahan dalam realitas kehidupan masyarakat modern, dan menjadi perhatian khusus Biennale Jatim hingga melakukan eksplorasi dan produksi karya seni yang mencoba melawan hegemoni dari informasi hoax dengan melakukan reproduksi informasi hoax.

Proses gerakan sosial dalam format digital dilakukan oleh Biennale Indonesia dengan mereproduksi karya seni untuk menangkal dominasi dan hegemoni fenomena hoax di Indonesia. Teknologi digital telah memiliki efek luar biasa pada industri media, pemerintah, perdagangan, sektor industri informal, sumber daya manusia, perencanaan kota, layanan, bantuan bencana, kesehatan, pendidikan, agama, ekspresi seni dan budaya, di samping berbagai bidang lainnya (Zis, Effendi, \& Roem, 2021). Pembentukan hegemoni baru yaitu hegemoni digital. Hegemoni baru ini menjadi perhatian khusus bagi para seniman digital di Biennale Jatim. Melalui karyakarya format digital, para seniman juga mencoba mengkomunikasikan seni mereka sebagai bentuk perlawanan diam-diam, protes, dan kritik terhadap hegemoni yang terjadi di masyarakat, mengacu pada ideologi, norma, dan mitos (Kristiyono \& Ida, 2020).

Beberapa penelitian terdahulu yang relevan tentang Biennale Indonesia dan gerakan seni di Indonesia menjadi dasar analisis kesenjangan (gap of knowledge) pada penelitian ini. Penelitian pertama yang relevan yaitu berjudul Contemporary of Art Biennials oleh Raffa Niemojewski pada tahun 2009. Niemojewski (2009) meneliti khusus pada karya seni yang diciptakan dan dipamerkan pada Biennale di Asia dan Eropa. Penelitian tersebut menemukan sebuah kebaruan dan identitas pada tiap Biennale yang diselenggarakan. Kebaruan tersebut berupa media karya cipta seni hingga isu-isu yang diangkat dalam pameran (Niemojewski, 2018). Perbedaan penelitian ini dari penelitian terdahulu yaitu pada Biennale Jatim 8 ini menggunakan media sosial sebagai media komunikasi digital yang menunjukkan diskursus atau perubahan sosial pada Biennale Jatim. Perubahan tersebut ditunjukkan pada media komunikasi Instagram @biennalejatim8 sebagai bentuk identitas perubahan tersebut.

Penelitian terdahulu yang relevan kedua adalah berjudul Pemberian Penghargaan Dalam Pameran Besar Seni Lukis Indonesia dan Biennale Jakarta 1974-1989 yang dilakukan oleh Atmadiredji dan Ira Genardi Adriati pada 2019 (Atmadiredja \& Adriati, 2020). Penelitian terdahulu ini lebih memfokuskan pada proses kegiatan pameran Biennale Jakarta pada periode tahun 1974 hingga 1989. Periode ini merupakan periode dominasi kekuasaan rezim Orde Baru yang melakukan hegemoni hingga pada dunia seni di Indonesia. Kegiatan-kegiatan serimonial dan pemberian apresiasi seni sangat kental dengan politik.

Penelitian ini memberikan perbedaan dan kebaruan secara analisis teoretis dan praktis dibandingkan dengan penelitianpenelitian terdahulu tersebut. Penelitian mencoba membongkar pesan komunikasi yang diciptakan pada kegiatan Biennale Jatim tahun 2019 lalu. Pesan-pesan yang dikonstruksi menunjukkan sebuah perlawanan dan usaha perubahan wacana dalam komunitas seni Biennale Jatim.

Berdasarkan fenomena sosial dan realitas permasalahan yang ada pada Biennale Jatim seperti yang dijelaskan sebelumnya, maka penelitian ini menganalisis secara kritis dan mendalam untuk mendapatkan penggambaran secara rinci dan diskursus yang terjadi selama proses penciptaan karya seni pameran instalasi sebagai identitas komunitas seni Biennnale Jatim khususnya pada Biennale Jatim ke 8 (2019). Untuk dapat menganalisa proses diskursus yang terjadi selama Biennale Jatim 8 ini, penelitian ini menggunakan metode analisa wacana (discourse analysis) pada era digital 
dikarenakan medium obyek penelitian diambil pada media komunikasi digital yaitu media sosial Instagram akun @biennalejatim8 dan @biennalejatim. Penelitian ini mengangkat permasalahan tentang "Bagaimana Kontruksi Identitas pada Karya Seni Pameran Instalasi Biennale Jawa Timur sebagai Medium Komunikasi?".

Tujuan dari penelitian ini adalah menggambarkan proses penciptaan karya seni pameran instalasi sebagai identitas komunitas seni Biennale Jatim, menganalisa proses diskursus yang terjadi pada komunitas Biennale Jawa Timur selama proses penciptaan karya seni, dan menganalisa media komunikasi yang digunakan dalam kontruksi identitas digital komunitas Biennale Jawa Timur (Castells, 2010b). Manfaat penelitian ini adalah memberikan manfaat secara teoretis ilmu komunikasi dalam konteks seni dan budaya khususnya media komunikasi dan media culture studies, dan aplikasi analisa kritis teori kontruksi sosial (Berger \& Luckmann, 1991). Secara praktis, penelitian ini memberikan gambaran realitas sosial yang terjadi di masyarakat modern, khususnya masyarakat informasi, yaitu masyarakat yang terus berkembang dalam dunia digital dan terus berjejaring (Castells, 2011b; Giddens, 1991; Kristiyono, 2017).

\section{Metode}

Penelitian ini menggunakan pendekatan studi kualitatif dengan metode Analisa Wacana Digital (Digital Discourse Analysis), dengan menganalisa diskursus yang terjadi selama kegiatan Biennale Jatim 8, hingga menganalisa kontruksi identitas sosial pada komunitas seniman Biennale Jatim sebagai subyek penelitian. Obyek penelitian ini adalah pameran instalasi karya seni dan media publikasi di dunia digital khususnya media sosial Instagram yaitu akun@biennalejatim8dan@biennalejatim (Jones, Chik, \& Hafner, 2015).

Teknik pengumpulan data menggunakan observasi pada seniman yang tergabung komunitas seni Biennale Jatim dan meta-data discourse publikasi digital di media sosial instagram (@biennalejatim). Selain itu juga melakukan wawancara secara mendalam kepada beberapa narasumber (kurator dan humas Biennale Jatim \#8) untuk validasi data. Salah satu kurator yang diwawancarai, yaitu Syska Liana pada bulan September 2020.

Posting feed dan stories pada akun media sosial@biennalejatim8 dan @biennalejatim menjadi metadata discourse obyek penelitian ini. Penelitian ini dilakukan selama periode April-Agustus 2020 dengan menganalisa konten Instagram @biennalejatim8 dan@biennalejatim pada masa pra-produksi karya seni (November 2019) hingga pasca pameran Biennale Jatim 8 (Juni 2020). Akun Instagram @biennalejatim8 merupakan akun penyelenggaraan Biennale Jatim yang ke-8 tahun 2019, memiliki 1009 followers dan sudah mem-posting 162 konten feed. Akun Instagram @biennalejatim merupakan akun Biennale Jatim. Akun ini merupakan media komunikasi penyelenggaraan Biennale Jatim 6 (2015) dan Biennale Jatim 7 (2017), memiliki 895 followers dan sudah memposting 145 feeds. Akun ini pertama kali memposting konten pada Agustus 2015 dan terakhir memposting feed pada Maret 2018 (sumber: data akun Instagram @biennalejatim8 dan @biennalejatim, terakhir akses Juli 2020).

Analisis wacana digital (digital discourse analysis) terletak di persimpangan bahasa, masyarakat, dan teknologi. Peneliti digital dapat memanfaatkan beragam disiplin bahasa yang berorientasi sosial, yang metode dan alat penelitiannya berguna dalam melakukan penelitian empiris. Metode penelitian ini perlu dinilai secara kritis dan diadaptasi secara reflektif, dan diperluas hingga dikombinasikan dengan metode atau teknik pengumpulan data lain untuk menjelaskan lebih rinci praktik komunikatif terutama pada dunia visual komunikasi yang terjadi di dunia digital (Blitvich \& Bou-Franch, 2019).

Wacana, dalam pandangan kontemporer yaitu lebih berkaitan dengan "praktik sosial" (Fairclough, 1992), dibandingkan bahasa 
yang digunakan. Pandangan awalnya mengenai wacana atau diskursus, cara pandang yang lebih sempit dan dipahami pada era tahun 1980 hingga 1990-an. Analisis wacana sebagai studi tentang "cara orang membangun dan mengelola dunia sosial mereka menggunakan berbagai sistem semiotik" (Jones et al., 2015).

Analisis wacana digital berkaitan dengan bagaimana sumber daya multimodal, multisemiotik digunakan untuk menetapkan identitas, kegiatan, dan ideologi di dunia digital, sebagai bagian dari dunia sosial yang lebih besar (Gee, 2005). Analisis wacana digital, merupakan analisa berbagai wacana yang dimediasi komputer, sosiolinguistik media baru atau bahasa dan komunikasi digital termasuk komunikasi visual.

\section{Hasil dan Pembahasan}

\subsection{Penciptaan Karya Seni Pameran Instalasi sebagai Identitas Komunitas Seni Biennale Jatim 8}

Konstruksi sosial memiliki arti yang luas dalam ilmu-ilmu sosial. Hal ini sering dikaitkan dengan pengaruh sosial dalam pengalaman hidup individu. Asumsi dasar "realitas adalah konstruksi sosial" dalam pandangan Berger dan Luckmann (Berger \& Luckmann, 1991). Selain itu, dikatakan bahwa konstruksi masyarakat memiliki beberapa keunggulan. Pertama, peran sentral bahasa menyediakan mekanisme khusus, yaitu budaya mempengaruhi pemikiran dan perilaku individu. Kedua, konstruksi sosial dapat mewakili kompleksitas dalam budaya yang sama, yang tidak menunjukkan homogenitas. Ketiga, sesuai dengan masyarakat dan masanya.

Komunitas seni Biennale Jatim mengalami pergeseran dan perubahan yang cukup besar dari waktu ke waktu, terutama pada penyelenggaraan Biennale Jatim ke 8 (tahun 2019). Budaya kontemporer yang terus berubah seiring dengan perubahan waktu dan teknologi mempengaruhi hingga memberikan pemikiran dasar pada seniman-seniman muda di Jawa Timur. Seniman-seniman kontemporer Jawa Timur yang tergabung pada komunitas seni Biennale Jatim ini mengalami perubahan ideologi, pemikiran, hingga tingkah laku yang tidak sama dengan seniman Biennale Jatim terdahulu. Kontruksi sosial yang tercipta oleh komunitas seni Biennale Jatim ini menunjukkan kompleksitas dalam satu budaya tunggal yaitu Biennale Jatim itu sendiri.

Cara pandang tentang konstruksi sosial adalah semua mengenai nilai, ideologi, dan institusi sosial. Semua itu merupakan buatan manusia dalam hal ini masyarakat atau komunitas seni Biennale Jatim. Untuk memahami dan menghargai implikasi penuh dari kontruksi sosial yang terjadi pada Biennale Jatim ini memerlukan waktu tersendiri. Kontruksi sosial adalah sebuah pernyataan keyakinan (a claim) dan juga sebuah sudut pandang (a viewpoint) bahwa kandungan dari kesadaran, dan cara berhubungan dengan orang lain itu diajarkan oleh kebudayaan dan masyarakat.

Pernyataan mengenai konsep dasar penyelenggaraan Biennale yang harus sakral dan harus diselenggarakan pada satu lokasi utama merupakan pernyataan yang selama ini diyakini oleh komunitas Biennale Jatim termasuk Biennale selain Jatim seperti Biennale kota-kota lainnya (Jakarta, Yogyakarta, Makassar, dan sebagainya) di Indonesia, bahkan Biennale luar Indonesia. Biennale merupakan pameran karya seni yang diselenggarakan dalam periode 2 (dua) tahunan, dan menjadi kebiasaan diselenggarkan di kota-kota besar pada daerah komunitas Biennale tersebut. Kebiasaan yang menjadi keyakinan (a claim) dan sudut pandang (a viewpoint) yang diajarkan oleh komunitas Biennale Jatim sebagai sebuah kebudayaan dan masyarakat. Cara pandang ini yang dibongkar dan dilawan pada penyelenggaraan Biennale Jatim 8, ini menunjukkan kontruksi sosial.

Pemahaman individu tentang dunia, pengetahuan, dan ego terbentuk di bawah kondisi historis dan sosial tertentu. Pengetahuan dan realitas konkrit dihubungkan oleh apa yang disebut Foucault sebagai wacana, yaitu ide-ide dan argumen-argumen tertentu yang secara langsung terkait dengan teknik-teknik penguasaan dan kekuasaan. 

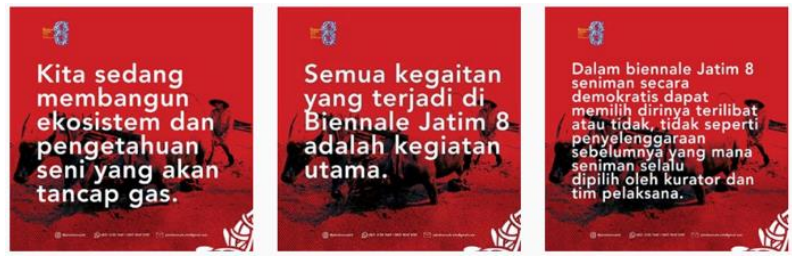

Gambar 1. Visual Grafis Posting Feed Instagram @biennalejatim8

(sumber: posting Feed @biennalejatim8 pada tanggal 12 Desember 2019)

$\begin{array}{ccc}\begin{array}{c}\text { Apapun } \\ \text { kekuasaan }\end{array} & \begin{array}{c}\text { sumber } \\ \text { menentukan }\end{array} & \begin{array}{c}\text { kekuasaannya, } \\ \text { pengetahuan, }\end{array}\end{array}$ membuat penilaian tentang apa yang baik dan apa yang buruk, apa yang baik dan apa yang tidak, mengatur perilaku, disiplin, dan kontrol segalanya, dan bahkan menghukumnya. Artinya, subjek manusia sebagai individu juga dibentuk dan diatur oleh rezim kekuasaan, dalam hal ini dominasi stigma yang dikonstruksi oleh Biennale Jatim. Hal ini dapat menggambarkan bagaimana konstruksi sosial dapat mempengaruhi hingga merubah perilaku dan orientasi sosial (Fairclough, 1992). Teori sosial ini menjadi dasar analisa diskursus dalam penelitian ini, bagaimana wacana atau diskurus yang terbentuk dalam proses interaksi sosial hingga kontruksi sosial di Komunitas Seni Biennale Jatim selama proses pameran karya Biennale Jatim \#8.

Biennale Jatim 8 berbeda dengan beberapa penyelenggaraan sebelumnya. Hal ini dituangkan dalam wacana kritis dalam medium komunikasi baik secara tekstual maupun secara visual grafis. Perbedaan Biennale Jatim dari segi penyelenggaraan, pendanaan, format acara, lokasi berlangsungnya kegiatan, hingga proses kuratorial karya seni dikomunikasi secara tegas pada media sosial Instagram @biennalejatim8. Ajang Biennale sebelumnya adalah event yang dianggap sakral, prestise, mewah, adiluhung, kualitas super, dikontruksikan berlawanan pada Biennale Jatim 8. Biennale Jatim 8 berusaha mendobrak stigma tersebut dan dikomunikasikan secara visual pada karya seni dan media komunikasi publikasi Instagram. Tema "GAS TOK! Lebur Sakjeroning Jawa Timur", menunjukkan pemosisian gelaran Biennale Jatim adalah milik dan melebur bersama masyarakat Jawa Timur. Pagelaran karya seni dalam format Biennale yaitu sebagai sebuah perayaan dan imajinasi bersama yang bersifat inklusif, tidak ada sekat, dan tanpa lokasi pameran utama (crown venue) yang selama ini menjadi stigma dan keharusan dalam proses pagelaran Biennale Jatim.

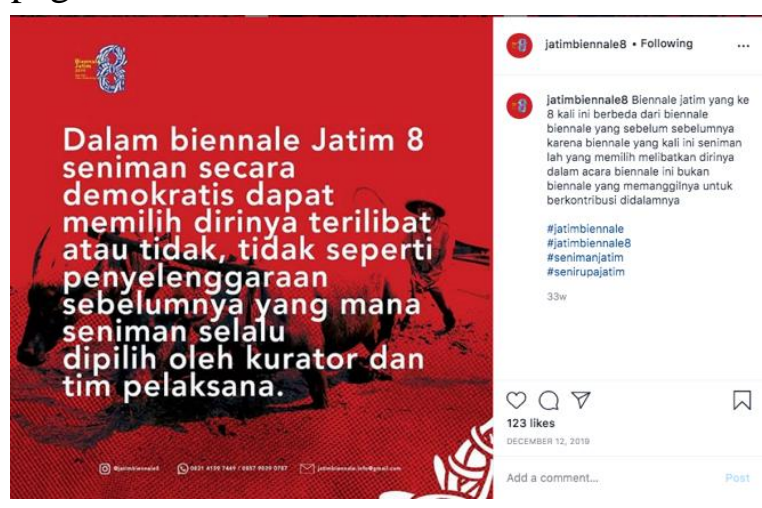

Gambar 2. Infografis dan caption posting feed Instagram @biennalejatim8 pada Biennale Jatim 8 2019

(sumber: posting Feed @ biennalejatim8 pada tanggal 12 Desember 2019)

Biennale Jatim 8 memberikan kebebasan demokratis dalam proses penciptaan karya seni hingga proses kuratorialnya. Ini yang menjadi perbedaan yang cukup signifikan dibandingkan dengan proses produksi karya seni Biennale Jatim sebelumnya. Visual infografis dan tekstual caption feed Instagram akun@biennalejatim8 menunjukkan sebuah proses diskursus kontruksi sosial yang dibangun. Sebuah diskursus perubahan sosial ditunjukkan pada teks-teks dan visual grafis di media sosial Instagram tersebut. Identitas baru sebagai diskursus ideologis Biennale Jatim ini yang ditunjukkan pada proses pra-produksi hingga produksi karya seni.

Biennale Jatim 8 melibatkan lebih dari 500 seniman dan lebih dari 40 kurator. Biennale Jatim 8 diselenggarakan lebih dari 65 kegiatan yang tersebar di 16 kota dan kabupaten di Jawa Timur. Biennale Jatim 8 ini sangat berbeda dengan kegiatan Biennale Jatim sebelumnya, selain lokasi pameran 
seluruh arsip data dan dokumentasi kegiatan rangkaian Biennale Jatim 8 dikumpulkan dan dipublikasikan melalui akun Instagram @jatimbiennale8. Kegiatan bersama yang inklusi menunjukkan perbedaan dari Biennale Jatim terdahulu yang bersifat lebih eksklusif, mulai pemilihan seniman, produksi karya seni, proses kuratorial karya seni hingga pagelaran seni Biennale Jatim.

Hasil penelitian ini berbeda dari penelitian terdahulu yang dilakukan Raffa Niemojewski pada tahun 2009 (Niemojewski, 2009). Obyek penelitian yang dilakukan Niemojewski (2009) merupakan pameran karya seni secara fisik sedangkan pada Biennale Jatim 8 ini menggunakan media sosial sebagai media komunikasi digital pameran karya seni. Selain itu media komunikasi digital Instagram ini menunjukkan diskursus atau perubahan sosial pada Biennale Jatim. Perubahan tersebut ditunjukkan pada media komunikasi Instagram @biennalejatim8 sebagai bentuk identitas perubahan tersebut (Djatiprambudi, 2005; Kusmara, 2019).

\subsection{Konstruksi Identitas Digital Komunitas Biennale Jatim 8}

Perkembangan teknologi dan komunikasi di Indonesia telah mengubah dan membentuk kehidupan sosial masyarakat Indonesia dalam ekspresi elektronik dengan media sosial, TV, film, game, foto digital yang terhubung secara digital dengan dunia internet. Perkembangan teknologi komunikasi digital membawa imajinasi masyarakat menembus batas-batas realitas sosial. Hingga terjadilah realitas semu dengan memanipulasi realitas sosial yang nyata, sehingga seolah-olah manusia sebagai entitas sosial bergerak dan hidup dari dunia nyata ke dunia imajiner atau dunia maya seolah-olah nyata. Semua yang nyata kini hanyalah simulasi (Baudrillard, 1994).

Semua kehidupan manusia saat ini berkembang seperti badai yang semu dengan adanya perkembangan dunia internet. Media digital tumbuh sangat masif dan dengan mudah berubah untuk berkembang dalam berbagai bentuk. Kecepatan penyebaran informasi digital di dunia internet society semakin tinggi membuat realitas dunia nyata menjadi besar (Castells, 2010a; Zis et al., 2021). Efek dari teknologi digital menimbulkan perluasan dan peningkatan bentuk konektivitas, juga mengarah pada bentuk informasi yang berlebihan hingga mengakibatkan disrupsi informasi. Kesalahan komunikasi dan informasi yang salah, menimbulkan efek negatif pada kehidupan sosial budaya yang dramatis dan terkadang fatal.

Kemajuan teknologi informasi dan komunikasi memberikan kebebasan kepada masyarakat untuk berimajinasi dan mewujudkannya. Sifat digital dan maya (virtual) juga semakin diperkaya dengan munculnya nyata dan palsu. Salah satunya adalah sinema atau film. Sebagai media massa, sinema merupakan tempat kebebasan berimajinasi (Kristiyono \& Sirikit, 2019). Analisis perkembangan dunia digital tidak akan memisahkan realitas sosial masyarakat, dari segi faktor pekerjaan, budaya, interaksi sosial dari sudut pandang ekonomi, politik dan sosial budaya (Sudiasmo, 2017).

Kajian ini menganalisis konstruksi identitas Biennale Jawa Timur di dunia digital dari perspektif sosial budaya Manuel Castells dan Baudrillard. Kecepatan perkembangan dan perkembangan teknologi informasi dan komunikasi di Indonesia sangat pesat, masyarakat sosial di Indonesia kini juga saling terhubung satu sama lain, tidak dibatasi oleh ruang dan waktu, dan komunitas sosial inilah yang disebut masyarakat informasi (Baudrillard \& Lane, 2000; Castells, 2010b; Jurriëns \& Tapsell, 2017).

Menurut Castells masyarakat informasi memiliki beberapa sudut pandang terhadap perkembangan masyarakat informasi, yaitu informasiisme, masyarakat berjejaring, ekonomi global atau ekonomi informasi, transformasi tenaga kerja, kota global dan budaya siber (Castells, 2011b). Berikut ini metadata discourse yang diambil dari akun Instagram @biennalejatim dan @biennalejatim 8 sebagai obyek penelitian 
analisa wacana digital (digital discourse analysis) dalam penelitian ini.

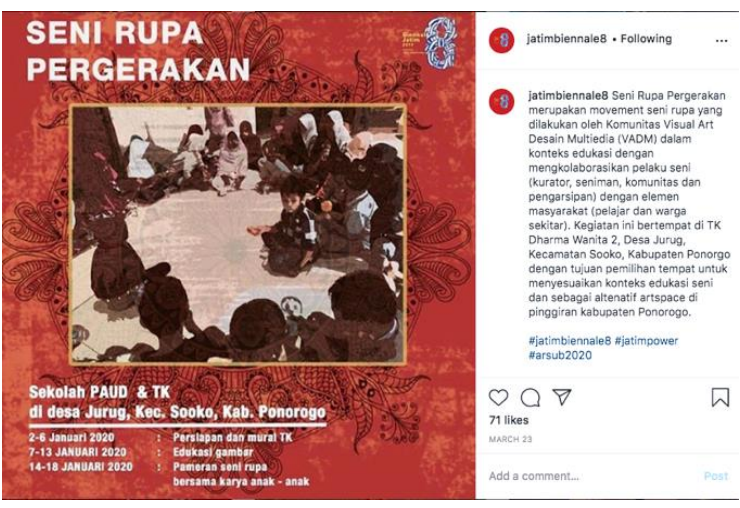

Gambar 3. Infografis dan caption posting feed Instagram tentang pergerakan seni rupa (sumber: posting Feed @ biennalejatim8 pada tanggal 12 Desember 2019)

Akun instagram@biennalejatim terdapat total 145 posts dan @ biennalejatim8 total 162 posts feed. Pada penelitian dianalisa secara purposive sampling dipilih konten-konten feed yang menunjukkan diskursus yang terjadi pada Biennale Jatim. Studi dan imajinasi praktik seni Biennale dalam pandangan politik, sosial dan budaya mengenai karya seni, lokasi pameran hingga proses kurasi mengungkap fenomena mengenai keterposisian subyek dengan keberadaan tempat (geopolitik). Selama 2 Biennale sebelumnya (2015 dan 2017) menunjukkan pagelaran seni yang inklusif dan sakral, ini ditunjukkan pada teks dan visual konten Instagram @ biennalejatim. Di sisi lain,pada akun instagram @biennalejatim8, menunjukkan teks dan visual perlawanan hingga perubahan pada geopolitik yang mendasari pagelaran Biennale Jatim. Karya seni bukan hanya berupa karya seni yang tidak bergerak dan dipamerkan pada ruang pamer yang sakral dengan proses diskusi dan kuratorial yang eksklusif dikulik fenomena tersebut oleh Vista Underated salah satu komunitas seni yang berpartisipasi pada Biennale Jatim 8.

Wacana ini dikomunikasikan dalam bentuk digital pada konten feed instagram @biennalejatim8 dengan upaya memetakan beberapa lokasi-lokasi yang terpinggirkan. Lokasi yang sesungguhnya selalu terasa asing. Pameran Biennale yang selalu terpusat pada kota besar (Surabaya, Jakarta, Yogyakarta, Makassar, Bandung, dan lainnya) merupakan isu geopolitik dituangkan dalam bentuk konstruksi ruangruang yang terpinggirkan dan menciptakan situasi kesaling-tergantungan subyek dengan lokalitas yang ada. Pameran dan pagelaran karya seni Biennale Jatim 8 tahun 2019 ini tersebar pada 16 kota di Jawa Timur, sangat berbeda dengan Biennale Jatim sebelumnya yang menempatkan kota Surabaya sebagai Crown Venue Biennale.

Perkembangan seni kontemporer komunitas Biennale Jatim ditunjukkan melalui Seni Rupa Pergerakan yang dilakukan oleh Komunitas Visual Art Desain Multiedia (VADM) dalam konteks edukasi dengan mengkolaborasikan pelaku seni (kurator, seniman, komunitas dan pengarsipan) dengan elemen masyarakat (pelajar dan warga sekitar). Kegiatan ini bertempat di TK Dharma Wanita 2, Desa Jurug, Kecamatan Sooko, Kabupaten Ponorgo dengan tujuan pemilihan tempat untuk menyesuaikan konteks edukasi seni dan sebagai altenatif artspace di pinggiran kabupaten Ponorogo.

Perkembangan seni kontemporer yang selalu bergerak, tidak diam pada menara gading akademis dan praktik seni yang berorientasi pada seniman selaku pencipta karya seni didobrak melalui kegiatan Seni Rupa Pergerakan ini. Perubahan sosial dan kontruksi identitas sosial ditunjukkan oleh pelaku seni yaitu VADM, sebuah komunitas seni yang diisi oleh para seniman muda generasi $\mathrm{Z}$ dan $\mathrm{Y}$ (Zis et al., 2021). Gerakan perlawaan sebuah hegemoni dan dominasi seni yang selama ini menempatkan karya seni (termasuk seniman pencipta karya seni) sebagai pusat perhatian pameran karya. Dengan melakukan kolaborasi dan elaborasi bersama masyarakat, praktik seni dilakukan bersama-sama dengan masyarakat tanpa batasan ruang. Konten feed dan caption tekstual ditunjukkan pada akun instagram 
@biennalejatim8 sebagai kontruksi identitas digital komunitas seni Biennale Jatim.

Terdapat novelty atau kebaruan dari penelitian ini dari penelitian terdahulu yang berjudul "Pemberian Penghargaan Dalam Pameran Besar Seni Lukis Indonesia dan Biennale Jakarta 1974-1989" yang dilakukan oleh Atmadiredji dan Ira Genardi Adriati pada tahun 2019 (Atmadiredja \& Adriati, 2020). Periode obyek penelitian terdahulu ini merupakan periode rezim Orde Baru yang melakukan dominasi kekuasaan dan hegemoni hingga pada dunia seni di Indonesia.

Perbedaan dan kebaruan secara analisis teoretis dan praktis dibandingkan dengan penelitian terdahulu tersebut adalah wacana atau diskursus fenomena sosial yang terjadi sebagai obyek penelitian. Hasil dari penelitian adalah pesan komunikasi yang diciptakan atau dikonstruksi pada pesan media digital sebagai bentuk kontruksi identitas (Castells, 2011a; Hatley, 2015). Pesan-pesan yang dikontruksi menunjukkan sebuah perlawanan dan usaha perubahan wacana dalam komunitas seni Biennale Jatim.

\section{Kesimpulan}

Kesimpulan yang dihasilkan pada penelitian ini, pertama adalah kebebasan demokratis yang diberikan Biennale Jatim 8 dalam proses penciptaan karya seni hingga proses kuratorialnya karya seni. Analisa wacana digital pada akun Instagram @biennalejatim8 dan @biennalekatim menunjukkan perbedaan yang cukup signifikan proses produksi karya seni Biennale Jatim tiap pagelaran pameran 2 tahunan (Biennale). Visual grafis sebagai media komunikasi visual hingga caption feed tekstual Instagram akun @biennalejatim8 menunjukkan proses diskursus konstruksi sosial yang dibangunnya. Sebuah diskursus perubahan sosial ditunjukkan pada teks-teks dan visual grafis di media sosial Instagram tersebut. Identitas baru sebagai diskursus ideologis Biennale Jatim ini yang ditunjukkan pada proses pra-produksi hingga produksi karya seni. Biennale Jatim 8 melibatkan lebih dari 500 seniman dan lebih dari 40 kurator. Biennale Jatim 8 diselenggarakan lebih dari 65 kegiatan yang tersebar di 16 kota dan kabupaten di Jawa Timur.

Kesimpulan kedua yaitu pada implikasi teoretik tentang analisa wacana digital, penelitian ini menghasilkan revisi paradigma dalam pandangan penelitian masa lalu, sekarang, dan masa depan dan menganalisis bagaimana pengguna informasi menyebarkan kekayaan sumber daya multimoda yang diberikan oleh teknologi digital untuk melakukan tugas dan untuk menetapkan identitas. Dalam bagian ini Biennale Jatim mengidentifikasi ideologi yang menopang konstruksi teks digital di dunia sosial (media sosial Instagram akun @biennalejatim8 dan @ biennalejatim). Kontribusi penting untuk studi wacana digital akan memiliki daya tarik interdisipliner di bidang sosio-linguistik, analisis wacana, studi gender, multimodality, studi media komunikasi, Desain Komunikasi Visual (DKV), dan seni pertunjukkan di era digital.

Penelitian ini masih dapat dikembangkan lebih lanjut sebagai bentuk pengembangan analisis hasil dari fenomena sosial di dunia seni media secara kontemporer. Dunia seni yang selalu berkembang baik format media karya cipta, isu-isu yang diangkat oleh seniman digital Indonesia, hingga gerakan-gerakan seni di Indonesia yang berbasis kultural. Menarik untuk dikaji lebih lanjut tentang permasalahan dan fenomena seni media di Indonesia, menggunakan teori-teori analisis media dan komunikasi sebagai pisau bedah, hingga metode-metode penelitian yang terbarukan seperti digital discourse analysis (Blitvich \& Bou-Franch, 2019; Jones et al., 2015).

\section{Ucapan Terima Kasih}

Peneliti mengucapkan terima kasih dan memberikan apresiasi tertinggi kepada Syska selaku Humas dan rekan-rekan seniman pada pagelaran Biennale Jatim 8. Diskusi dan dialog kritis konstruktivisme selalu dibangun dengan oleh Biennale Jatim. Wacana dan tindakan praxis menjadi bukti kuat bahwa 
Biennale Jatim dan Biennale Indonesia merupakan komunitas seniman kontemporer yang selalu bergerak dan terus membangun perkembangan seni di Indonesia.

Peneliti juga mengucapkan terima kasih sebesar-besarnya kepada Prof. Rachmah Ida yang selalu memberikan ide dan bimbingan dalam mengeksplorasi riset-riset berbasis studi media \& budaya, dan digital visual art.

\section{Daftar Pustaka}

Atmadiredja, G., \& Adriati, I. (2020). Pemberian penghargaan dalam pameran besar seni lukis Indonesia dan Biennale Jakarta 1974-1989. Mudra Jurnal Seni Budaya, 35(1), 7-14, https://jurnal.isidps.ac.id/index.php/mudra/article/down load/692/460/2044

Baudrillard, J. (1994). Simulacra and simulation / by Jean Baudrillard; translated by Sheila Faria Glaser. Idea (Vol. 29). https://doi.org/10.1017/S13591355000 01081

Baudrillard, J., \& Lane, R. J. (2000). Jean Baudrillard-Routledge critical thinkers. Routledge Critical Thinkers.

Berger, P. L., \& Luckmann, T. (1991). The social construction of reality: A treatise in the sociology of knowledge. Penguin Uk.

Black, J., Castro, J., \& Lin, C. (2015). Youth practices in digital arts and new media: Learning in formal and informal settings. Springer.

Blitvich, P. G.-C., \& Bou-Franch, P. (2019). Introduction to analyzing digital discourse: New insights and future directions. In Analyzing Digital Discourse (pp. 3-22). Springer

Castells, M. (2010a). The information age: Economy, society and culture. Volume III: End of Millennium. Cambridge MA and Oxford UK Blackwell. https://doi.org/10.1002/9781444318234
Castells, M. (2010b). The power of identity. The information age economy society and culture. https://doi.org/10.1002/9781444318234

Castells, M. (2011a). The power of identity: The information age: Economy, society, and culture (Vol. 2). John Wiley \& Sons.

Castells, M. (2011b). The rise of the network society: The information age: Economy, society, and culture (Vol. 1). John Wiley \& Sons.

Djatiprambudi, D. (2005). Pembentukan seni rupa modern di Asia Tenggara. Jurnal Seni Rupa FBS Unimed, 2(01), 15-26, http://digilib.unimed.ac.id/360/1/Pemb entukan\%20seni\%20rupa\%20modern\% 20di\%20Asia\%20Tenggara.pdf

Effendy, R. (2012). Equator's heat: Biennale Jogja XI 2011. Art Monthly Australia, (247), 32-35, https://search.informit.com.au/docume ntSummary; $\mathrm{dn}=321147501840087$;res =IELLCC

Fairclough, N. (1992). Discourse and social change (Vol. 10). Polity press Cambridge.

Gee, J. P. (2005). The new literacy studies: From'socially situated'to the work. Situated Literacies: Reading and Writing in Context, 2, 177-194, https://www.researchgate.net/publicatio n/247932274_The_New_Literacy_Stud ies_From"socially_situated"to_the_wor k_of_the_social

Giddens, A. (1991). Modernity and selfidentity. Self and Society in the Modern Age. Corrosion

Hatley, B. (2015). Performing contemporary Indonesia: Celebrating identity, constructing community. Brill.

Hudayana, B. (2021). Pengembangan seni- 
budaya sebagai penguatan identitas komunitas kejawen dan santri di desa pada era reformasi. Satwika: Kajian Ilmu Budaya Dan Perubahan Sosial, 5(1), 1-17.

Ida, R. (2010). Reorganisation of media power in post-authoritarian Indonesia: Ownership, power and influence of local media entrepreneurs. In Politics and the Media in Twenty-First Century Indonesia: Decade of Democracy. https://doi.org/10.4324/9780203840429

Jones, R. H., Chik, A., \& Hafner, C. A. (2015). Discourse and digital practices: Doing discourse analysis in the digital age. Routledge.

Jurriëns, E., \& Tapsell, R. (2017). Digital Indonesia: connectivity and divergence. ISEAS-Yusof Ishak Institute.

Kristiyono, J. (2017). Budaya internet: Perkembangan teknologi informasi dan komunikasi dalam mendukung penggunaan media di masyarakat. $\begin{array}{lll}\text { Scriptura, } & 5(1), & \text { 23-30. }\end{array}$ https://doi.org/10.9744/scriptura.5.1.23 $-30$

Kristiyono, J., \& Ida, R. (2019). Digital etnometodologi: Studi media dan budaya pada masyarakat informasi di era digital. ETTISAL: Journal of Communication, 4(2), 109-120, https://doi.org/10.9744/scriptura.5.1.23 -30 .

Kristiyono, J., \& Ida, R. (2020). Counterhegemony of the East Java Biennale art community against the domination of hoax content reproduction. Masyarakat, Kebudayaan Dan Politik, 33(1), 26-35, http://dx.doi.org/10.20473/mkp.V33I12 020.26-35.

Kristiyono, J., \& Sirikit, H. (2019). Menelisik siasat cerita digital reality pada film ready player one? Bricolage: Jurnal Magister Ilmu Komunikasi, 5(2),
159-176, http://dx.doi.org/10.30813/bricolage.v5 i02.1885.

Kusmara, A. R. (2019). Karya-karya seni rupa kontemporer Indonesia berbasis media kertas: Bentuk dan wacana. Mudra Jurnal Seni Budaya, 34(2), 269274, https://doi.org/10.31091/mudra.v34i2.7 10.

Laraña, E., Gusfield, J. R., \& Johnston, H. (2009). New social movements: From ideology to identity. Temple University Press.

Niemojewski, R. (2009). The Rise of the contemporary biennial 1984-2009. PhD Thesis.

Niemojewski, R. (2018). Contemporary art biennials. Cultural Politics. https://doi.org/10.1215/174321974313065

Pavlik, J. V. (2008). Media in the digital age. Columbia University Press.

Sudiasmo, F. (2017). Nilai-nilai Islam dalam konstruksi sosial konservasi lingkungan pesisir (Studi di Mangrove Center Tuban). SATWIKA: Kajian Ilmu Budaya Dan Perubahan Sosial, 1(1) 14-27, https://doi.org/10.22219/satwika.v1i1.4 601.

Voragen, R. (2013). Biennale fever in Indonesia: Temporary sites for contemporary art. Art Monthly Australia, (265), 9-13.

Zis, S. F., Effendi, N., \& Roem, E. R. (2021). Perubahan perilaku komunikasi generasi milenial dan generasi $\mathrm{z}$ di era digital. Satwika: Kajian Ilmu Budaya Dan Perubahan Sosial, 5(1), 69-87, https://doi.org/10.22219/satwika.v5i1.1 5550 . 